\title{
Technological particularities of laser manufacturing
}

\author{
Daniel Besnea ${ }^{1, *}$, Alina Spanu ${ }^{1}$,Victor Constantin ${ }^{1}$, and Dontu Octavian ${ }^{1}$ \\ ${ }^{1}$ Politehnica University of Bucharest, Mechatronics and Precision Engineering Department, Splaiul \\ Independenţei, nr. 313, Bucharest, Romania
}

\begin{abstract}
The paper presents some investigations about the influence of the Nd:YAG laser welding parameters on the penetration and metal evaporation of single and dual pass weld in the case of thin sections of stainless steel sample. The metal loss during welding process was measured in order to establish the optimal values of welding parameters. The geometric size of the welded zone was measured using an SEM microscope in order to establish the correlation between the penetration and with at different values of welding parameters.
\end{abstract}

\section{Introduction}

Due to the advantages that laser provides, such as high temperature and strictly controlled time for warming, the minimum area of the narrow boundary along the welding line with thermal influence, the high speed for welding without supplementary material, the opportunity of entire automation, it is used widely in industry especially in the fields where there are stainless steel and aluminum. Some examples are from chemical, food, aeronautical and pharmaceutical industries.

We have to choose the laser provider device correctly in order to obtain the right laser welding. Meantime it is needed to adapt the type of joining and the used materials according to the strength of the process, which is using the optimum length of wave providing a great absorption of radiations.

The temperature increasing $\mathrm{T}_{\mathrm{m}}$ that is developed inside the welding area should be greater than the melting temperature $\mathrm{T}$ melting but lower than the temperature of vaporization, so that the parameters of laser radiations should be controlled as function of material type and part positions.

$$
T_{\text {melting }}<T_{m}<T_{\text {vaporisaton }}
$$

The working time of laser radiation is chosen according with maximum melting depth that should be done when the material of outside area has the boiling value, because of the melting front penetration. The penetration should start before the vaporization of shallow layer.

${ }^{*}$ Corresponding author: $\mathrm{d}$ bes@yahoo.com 
The rapid conduction of heat inside both materials along the welding area is depending on the material thermal diffusion $d$ as well as on the type of connection. Before the welding process, the parts should be cleaned from oxides and some other impurities, so the connection is an ideal one meaning there are not temperature discontinuities.

It is possible to evaluate the melting material depth using the laser welding, because we suppose there are no changes of specific heat coefficient of the material when they pass through melting point and the spatial laser profile is a Gaussian one.

The mathematical equation of material temperature as function of absorbed flow intensity $I_{0}$ is given below

$$
T_{(r, z, t)}=\frac{I_{0} a^{2}}{k} \quad \sqrt{\frac{d}{\pi}} \int_{0}^{\tau_{i}} e^{\frac{z^{2}}{4 d t} e^{r^{2}\left(4 d t+a^{2}\right)}} .
$$

As we infer from the equation above, it is depending on: area unit which is constant for period shorter than the period of laser pulse $\tau_{\mathrm{i}}$; radial distance $r$ from the center of laser wave; the material penetration depth $z$; time $t$

We may compute $\mathrm{I}_{0}$ as function of laser ray period taking into account the condition that the ray center $(r=0)$ on the material surface $(z=0)$ the temperature has its maximum value but lower than the vaporization temperature.

$$
\left.T(r, z, t)\right|_{\substack{r=o \\ z=0}}=T(0,0, t) \leq T_{\text {vaporisation }}
$$

The depth for material melting inside for specific laser working period is limited by the way the thermal field is spread inside the part. On its turn, it is depending on the material properties, the thermal characteristics before the laser ray action and the dimension of the part. We may define the thermal time constant $\mathrm{C}_{\mathrm{iT}}$ as the period when the temperature of melting material is about the same level of value with the temperature of surface warmed by the laser ray. For a extruded part with the thermal diffusion $d$ and the thickness $l$

$$
C_{i T}=\frac{l^{2}}{4 d}
$$

and it is a rough result for the time needed for the thermal flow propagation through a material layer during its melting. When the working period of laser ray is small than the thermal time constant of the material used for welding, it is not possible to obtain a homogeneous melting for the metalograph components of this material.

The focal distance of the optical system used for focusing the rays and the position of welding parts in directly relationship with the focal plane are other controlled parameter, which may influence the thermal distribution of temperature inside the material as well as the area melting by the laser.

Another important characteristic which may influence the quality of laser welding frame is given by the chemical reaction for oxydation or nitration with the gases inside the atmosphere by using high temperature level. It may causes some problems in case the oxides or some other resulted chemical elements have the temperature of dissociation higher than the melting point of the steel. Consequently the resulted welding area will be spongy and for avoiding it we should use an actionless gas [1-4].

In the following table 1 are shown some results of laser welding in the case of materials often used in mechatronics systems. 
Among all the other conditions specified above, we have to impose a high accuracy positioning of the part in front of laser ray for manufacturing the better quality laser welding taking into account the presence of the supplementary material needed.

This accurate positioning demands the part preparation very carefully as well as tolerance system dimension by comparison with other welding type. The positional errors along the movement axis should not exceed the focal ray radius. Consequently, the tolerance value of $0.1 \mathrm{~mm}$ is recommended, but for smaller dimensions it has to be reduced [5-6].

Table 1.

\begin{tabular}{|c|c|}
\hline Material & Comments \\
\hline Aluminum 1100 & Welds well; no cracking problem or transformation \\
\hline Aluminum 2219 & No cracks; no filler metal required \\
\hline $\mathrm{Cu}-\mathrm{Zn}$ Brasses & Out-gassing of $\mathrm{Zn}$ prevents good welds \\
\hline Carbon Steel & $\begin{array}{l}\text { Good welds with carbon content under } 0.25 \% \text {; for greater carbon content, } \\
\text { may be brittle and crack }\end{array}$ \\
\hline $\begin{array}{l}\text { Galvanized } \\
\text { Steel }\end{array}$ & Severe Zn boil-off causes porosity \\
\hline $\begin{array}{l}\text { Steel, } 300 \\
\text { Stainless }\end{array}$ & Welds well, except 3030 and 303SE, which crack \\
\hline $\begin{array}{l}\text { Steel, } 400 \\
\text { Stainless }\end{array}$ & $\begin{array}{c}\text { Generally welds somewhat brittle; may require pre- and post-weld heat } \\
\text { treating }\end{array}$ \\
\hline $\begin{array}{l}\text { Steel, 17-4PH } \\
\text { Stainless }\end{array}$ & Needs post-weld heat treating to strengthen \\
\hline Tantalum & Ductile welds; special precautions against oxidation required \\
\hline Titanium & Ductile welds; special precautions against oxidation required \\
\hline Tungsten & Brittle welds; requires high energy \\
\hline Zirconium & Ductile welds; special precautions against oxidation required. \\
\hline
\end{tabular}

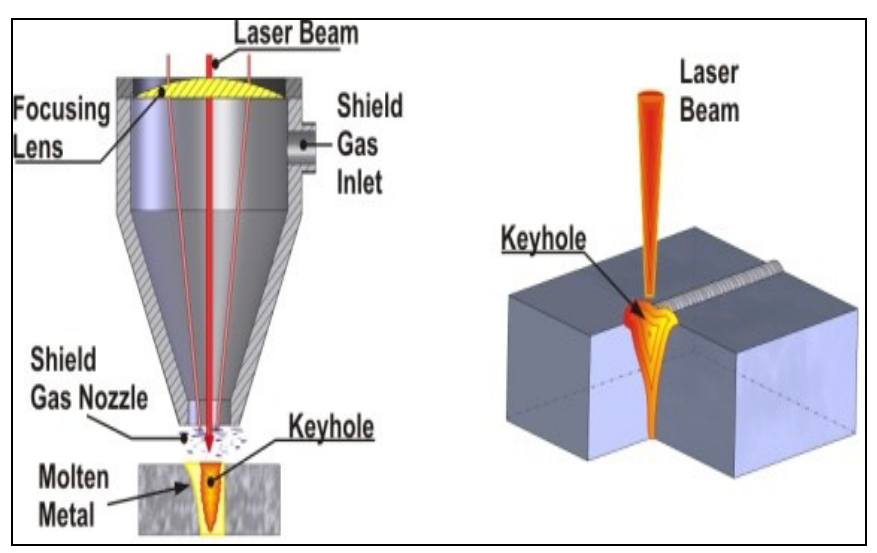

Fig. 1. The positioning of focal ray in the welding plane of part [5].

The positioning along the $\mathrm{Z}$ axis of laser ray is the easiest way due to the depth of the material if it is placed in the XY plane. For the smaller dimensions the ray is placed on the part surface and inside it for bigger ones.

Usually, the following values are used in practice:

- for thickness between 0.2 and $0.5 \mathrm{~mm}$ - it is accepted the join $\mathrm{J}$;

- for thickness between 1 and $2 \mathrm{~mm}$ - it is accepted the join;

- for thickness between 3 and $10 \mathrm{~mm}$ - it is accepted the join $\mathrm{J}$.

In table 2 there are presented the most important assembly types that could be manufactured with laser welding. 
Table 2. Assembly types

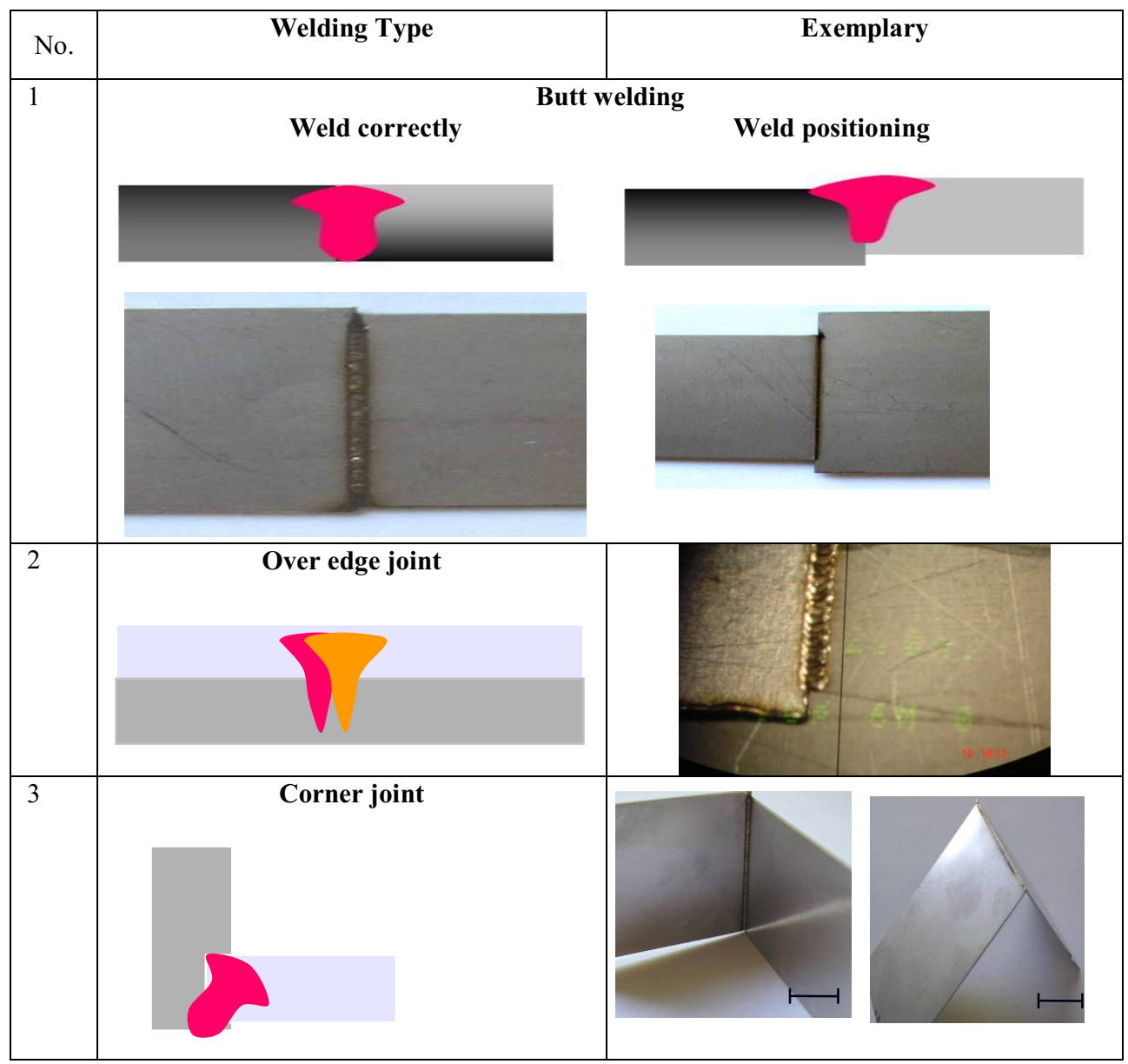

\section{Experimental researches}

The laser welding for high alloy stainless steel is widely used for accurate mechanical systems and industrial products. We present an example for Nd:YAG laser using for automatic welding of radiation source tightness made of stainless steel .

The capsule for radiation sources should be welded following high security conditions inside controlled atmosphere conditions. The experimental researches have been done using the laser system with solid activ environment Nd:YAG ROFIN Starweld SWP 6002 [9], equipped with numerical control, fig. 2. By choosing correctly the welding parameters, especially the energy values and the impulse period, there were possible to manufacture some welding capsules with high thermal module without a heavy load of additional material. The body and the head parts used as capsule assembly components are manufactured with circular welding. The capsules are made of 304 type stainless steel $10 \mathrm{TiNiCr} 180$ with a balanced austenitic structure (chemical formula $\mathrm{Fe}<0.08 \% \mathrm{C}, 17.5$ $20 \% \mathrm{Cr}, 8-11 \% \mathrm{Ni},<2 \% \mathrm{Mn},<1 \% \mathrm{Si},<0.045 \% \mathrm{P}<0.03 \% \mathrm{~S})$. The enclosed capsules for nuclear radiation used in non destructive testing or measuring application require a good sealing during the working period. The capsule assembly contains two pieces, the capsule body and the cover, which needs to be joined together by circular welding made on the 
capsule's top. In order to obtain a good quality sealing, laser welding process was applied to join cover to the capsul's body without filler metal. The dimensions of a capsule, figure 2 are: $5 \mathrm{~mm}$ in diameter and $8 \mathrm{~mm}$ in length $[2,5-6]$.
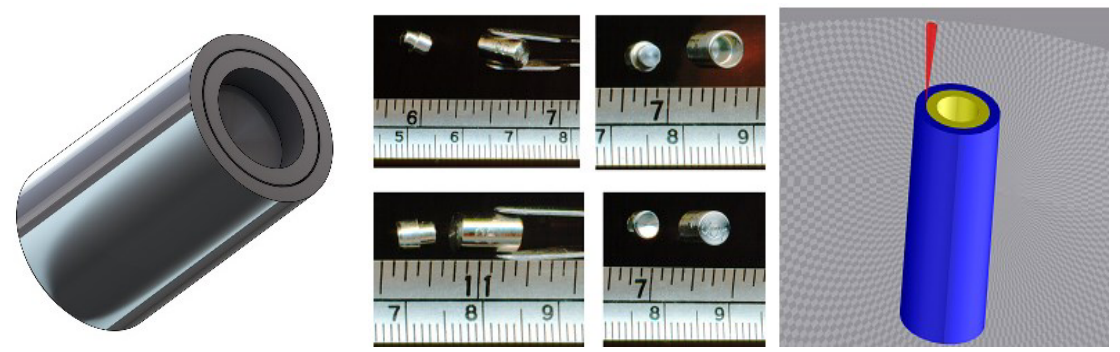

Fig. 2. The components and dimensions of the capsule.
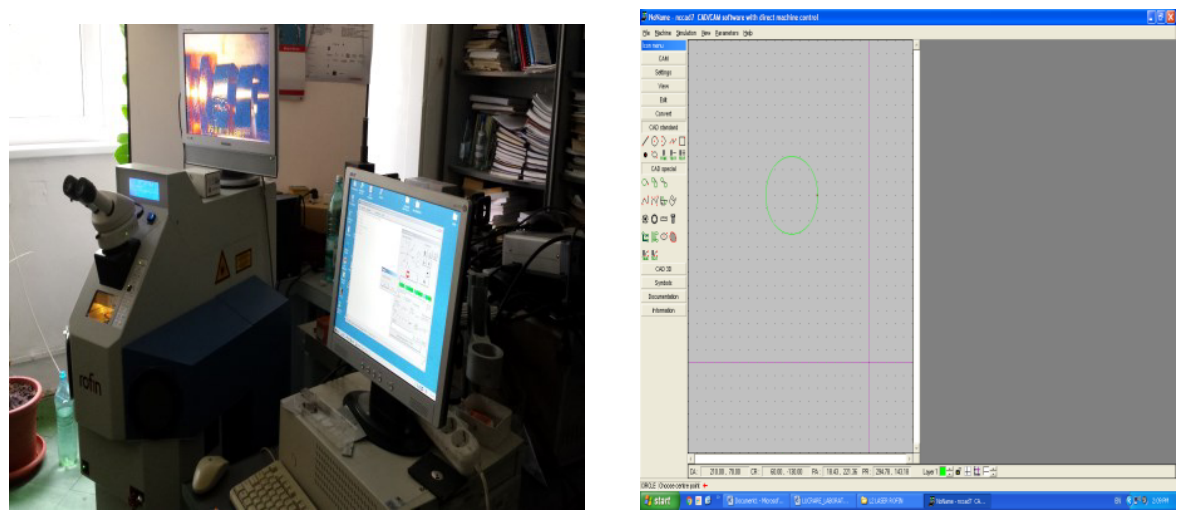

Fig. 3. The Nd:YAG Starweld SWP 6002 Rofin-CNC laser device for welding and the menu for the 2D design [9].

The software nccad_6 affords the opening of new file for designing or for changing the file. In the $\mathrm{CNC}$ menu we have the text editor for editing and for running. For a new model we use Fichier CAD/CAM - Nouveau dessin figure 3. If we want to work in CNC or $\mathrm{CAD} / \mathrm{CAM}$ we may use the menu for function CAM manufacturing, the edit group that allows the changes of a model, the CAD group that allows the design using the $\mathrm{XY}$ axis fig. 3 . The nccad_6 software allows working by following the rules imposed by ISO 66025 . At first the files are written inside a text editor, the graphical simulation could be done by working with Menu Simulation and finally the manufacturing is done by working with Menu Machine. Mainly, the G functions are used affording the movement and the machine functions are based on $M$ functions. Nearby all the working facilities specified before, we may use some complementary functions that may be recognized by their name with some blank spaces. As we may infer from fig. 4 the CNC package allows the transfer inside the working area based on the coordinate system [9].

\section{Experimental results and conclusions}

The micro-welding laser that works with impulses, produced by ROFIN company provides a better solution for rapid welding with high accuracy for all the steel materials and their used alloys inside a solid activ environment $\mathrm{Nd}$ :YAG with wave length $1.06 \mu \mathrm{m}$; the maximum energy of a pulse is $30 \ldots 110 \mathrm{~J}$. 

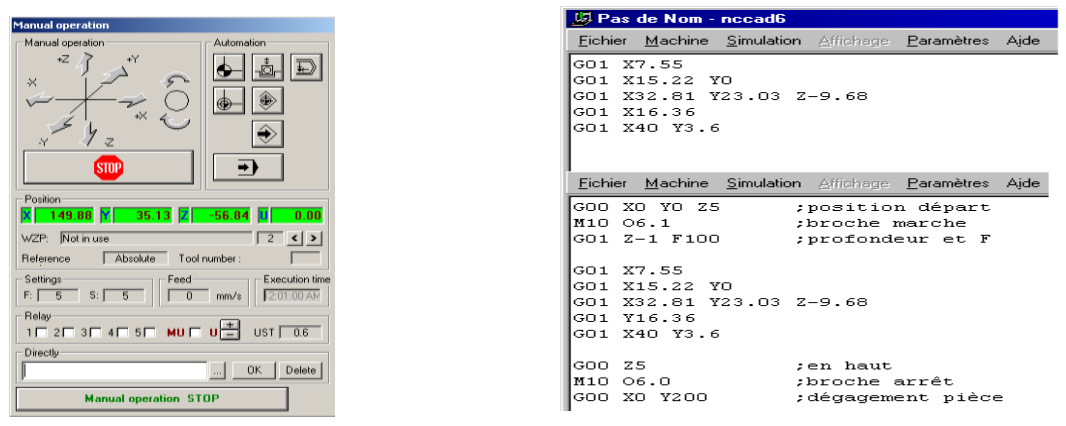

Fig. 4. The software written in nccad_6 language is transferred in the working environment [9].

The working power is $35 \ldots 60 \mathrm{~W}$ the maximum power of a pulse is $4.5 \ldots 10.6 \mathrm{~kW}$ the pulse frequency is $1 \ldots 20 \mathrm{~Hz}$; the pulse period is from 0.5 to $50 \mathrm{~ms}$; the working class is 4 .

The maximum length: $80 \times 80 \times 140$, maximum speed: $10 \mathrm{~mm} / \mathrm{s}$, accuracy: $<20 \mu$, resolution: $2.5 \mu \mathrm{m}$, maximum load: $20 \mathrm{~kg}$, maximum distance allowed for welding $400 \times 200 \times 100 \mathrm{~mm}$, the software for control nccad_6, the file type imported: 3D CAD (2D DXF, HPGL, 3D STL), the direct language programming NC ISO 66025. The control is made by using the microcontroller with external programming through RS 232 [9].

Finally we have tested the hardness by using a Shimadzu HMV $2 \mathrm{~T}$ and electronic microscopy with SEM INSPECT S microscope. The mass losses during the welding process was measured with an electronic balance ABJ 220 - 4M with $1 \mathrm{mg}$ accuracy. Before the welding the parts were cleaned in an ultrasonic system. In the Table 3 there are presented the working parameters for three tested parts [10-11].

A condition imposed by SR ISO 9978 standard stipulates that inside the capsule that contains radioactive material, the temperature should not exceed $95^{\circ} \mathrm{C}$. To determine the most suitable welding parameters to meet these requirement, a mathematical model of heat propagation inside the material was constructed [7-8].

This model was implemented in ANSYS software and a simulation was generated.

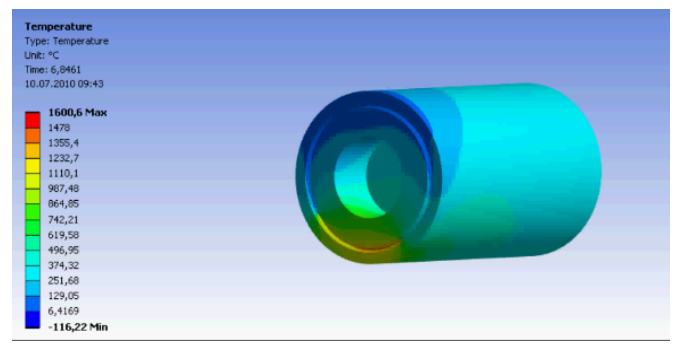

Fig. 5. Heat propagation simulation.

The simulation took into account an initial temperature of $20^{\circ} \mathrm{C}$, a perfect contact between the top of the capsule and the capsules body and a heat exchange with the environment by convection.

The simulation figure 5, showed a fast rise in temperature and also a fast cooling at the welding spot and a slow rise in temperature at the bottom of the capsule. This increase in temperature is not generated directly by the laser beam but by heat dissipation in material after applying the welding spot.

For the radioactive capsule having the working parameters P2. For the highest value of laser power the steel losses due to vaporization and penetration are maxim. The diminution of laser pulse period has produced an increase of width of welding stitch, breakings and 
porous surfaces (Fig. 7). Instead modifying the working parameters for welding sample P1 was executed correctly.

Table 3. Working parameters for three tested parts

\begin{tabular}{|c|c|c|c|c|c|c|c|}
\hline Sample & $\begin{array}{c}\text { Voltage } \\
{[\mathrm{V}]}\end{array}$ & $\begin{array}{c}\text { Pulse } \\
\text { time } \\
{[\mathrm{ms}]}\end{array}$ & $\begin{array}{c}\text { Beam } \\
\text { energy, } \\
{\left[\mathrm{J} / \mathrm{cm}^{2}\right]}\end{array}$ & $\begin{array}{c}\text { Pulse } \\
\text { frequency } \\
{[\mathrm{Hz}]}\end{array}$ & $\begin{array}{c}\text { Average } \\
\text { penetration } \\
{[\mu \mathrm{m}]}\end{array}$ & $\begin{array}{c}\text { Metal } \\
\text { loss } \\
{[\%]}\end{array}$ & $\begin{array}{c}\text { Spot } \\
{[\mathrm{mm}]}\end{array}$ \\
\hline P1 & 233 & 2.3 & 1275 & 2.6 & 337.54 & 0.36 & 0.775 \\
\hline P2 & 245 & 3.1 & 1895 & 2.3 & 577.72 & 1.28 & 0.775 \\
\hline P3 & 230 & 3.0 & 1249 & 2.0 & 413.22 & 0.39 & 0.95 \\
\hline
\end{tabular}
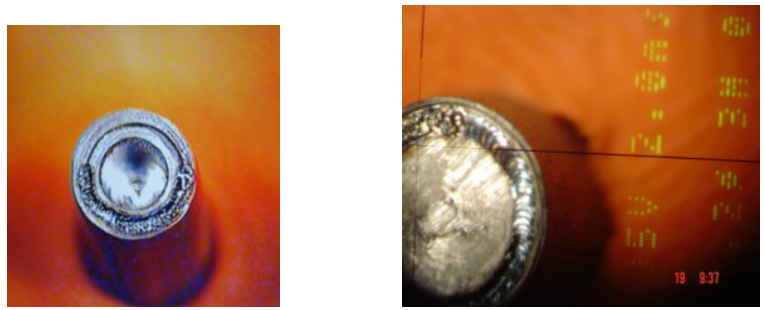

Fig. 6. The manufactured welding [9].

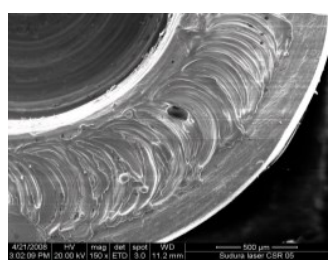

Fig. 7. The macrostructure for working parameters P2 [9].

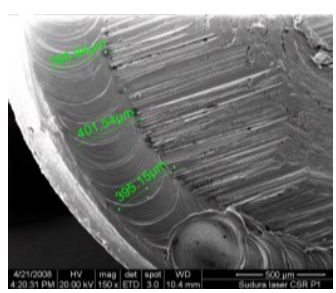

Fig. 8. The macrostructure for working parameters P1 [9].

The laser using for inscription, engraving and putting a mark on are very recent time applications.

These activities could be done with good efficiency on the laser systems characterized by continuous emissions $\left(\mathrm{CO}_{2}+\mathrm{He}+\mathrm{Ne}\right)$ as well as on the laser systems with discreet emissions, the later one with some disadvantages regarding the efficiency and the continuity of shapes.

The inscriptions, engraving and putting the marks on by laser using could be applied for steel, crystals (diamond, sapphire, ruby), glass and some other.

The part movement is done in front of laser ray controlled strictly by software and microcontrollers for laser provider and for mechanical part. In such case the symbol for engraving - putting the mark on is usually a numeric one, meaning a fully process automation (Fig. 11). 
In order to design a new model, we begin with a CAD /CAM file named Nouveau dessin (Fig. 9). The working space has the table dimensions $\mathrm{Y}$ left - right and $\mathrm{X}$ axis for the machine axis.

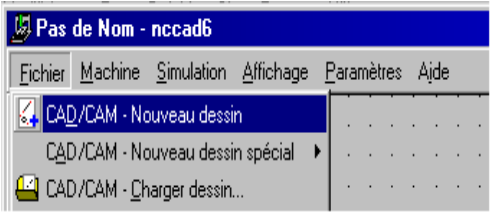

Fig. 9. The opening of $\mathrm{CAD} / \mathrm{CAM}$ working environment in a new file and the icon $\mathrm{CAD}$ standard.

For CAD file manufacturing we use the Technologies icon from group CAM. We continue with the placement of working point over the rectangle and we put the mark on. Inside the Technologies window we approve the values (Fig. 10).
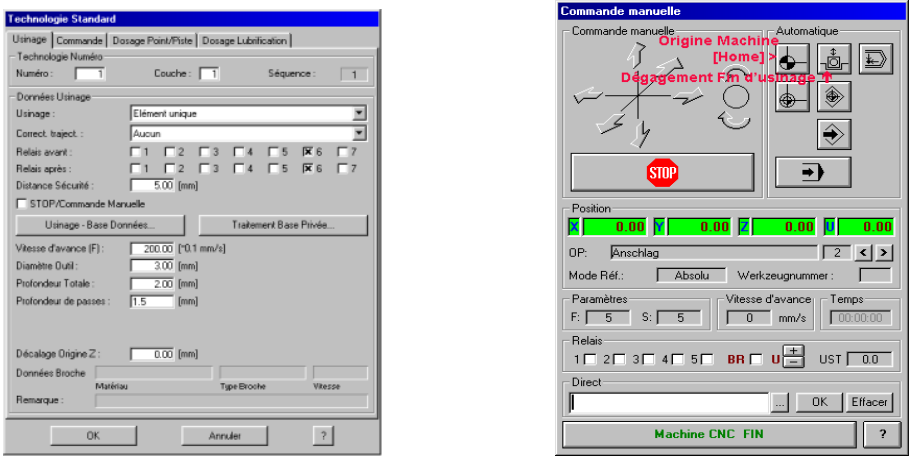

Fig. 10. The approval of the values and the command for setting the part origin.

From the window named Comande manualle belonging to Machine/Machine CNC menu we push the button Degagement fin d'usinage, figure 10. We continue with the operation for establishing the part origin, so that we start with Lancement du programe finally [9].

\begin{tabular}{|c|c|c|c|}
\hline $\begin{array}{l}\text { Welding Program } \\
\text { G00 Z-95 Y35 X35 } \\
\text { M05; } \\
\text { G91; } \\
\text { M10 O2.1; } \\
\text { Gas Power } \\
\text { M30 P18; } \\
\text { Pause } \\
\text { M10 O3.1 } \\
\text { Laser Power } \\
\text { G02 X0 Y0 I2 J2 F15; } \\
\text { M10 O3.0; } \\
\text { Laser stop } \\
\text { M10 O2.0; } \\
\text { Gas stop } \\
\text { M05; } \\
\text { G90 }\end{array}$ & $\begin{array}{l}\text { Gas Power } \\
\text { M30 P18;Pause } \\
\text { M10 O3.1 ; Laser } \\
\text { Power } \\
\text { M30 P25;Pause } \\
\text { M10 O3.0; Laser stop } \\
\text { G00 X35.24 Y33.02 } \\
\text { M10 O2.1; } \\
\text { M10 O2.0; Gas stop } \\
\text { G00 Y26.10 } \\
\text { M10 O2.1; } \\
\text { Gas Power } \\
\text { M30 P18 ;Pause } \\
\text { M10 O3.1 ; Laser } \\
\text { Power } \\
\text { M30 P25 ;Pause } \\
\text { M10 O3.0 ; Laser } \\
\text { stop } \\
\text { M10 O2.0 ; Gas stop }\end{array}$ & $\begin{array}{l}\text { M10 O2.1 ; Gas } \\
\text { Power } \\
\text { M30 P18 ;Pause } \\
\text { M10 O3.1 ; Laser } \\
\text { Power } \\
\text { M30 P25 ;Pause } \\
\text { G00 X39.21 } \\
\text { M10 O3.0; Laser stop } \\
\text { M10 O2.1 ; Gas } \\
\text { Power } \\
\text { M30 P18 ;Pause } \\
\text { M10 O3.1 ; Laser } \\
\text { Power } \\
\text { M30 P25 ;Pause } \\
\text { M10 O3.0 ; Laser } \\
\text { stop } \\
\text { M10 O2.0; Gas stop } \\
\text { M05 ; } \\
\text { G00 X37.17 Y34.1 }\end{array}$ & 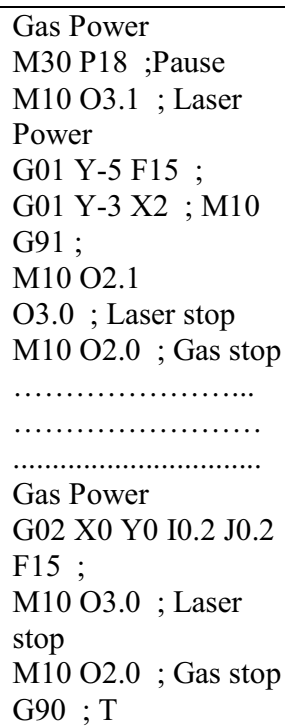 \\
\hline
\end{tabular}

Fig. 11. The engraving sequence. 


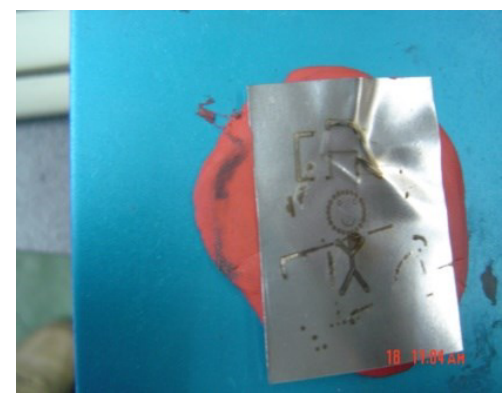

Fig. 12. Example of engraving with numerical control and the software sequence [9].

\section{Conclusions}

The originality of the paper is that it approaches a field of unconventional technology laser-welding with solid active medium YAG:Nd in CNC mode for obtaining radioactive capsules with applications in medical and nuclear fields, according to ISO2919 standards and ISO9978. Since the rules on nuclear radiation and radiation protection sources are very restrictive, the experimental research presented in the paper offers a solution to the realization of a viable welding cord and meeting these criteria of sealing. The metallographic analysis carried out on our team's laser micro-welding of radioactive capsules revealed the advantages of the method and the fulfillment of current ISO standards.

We have pointed out the opportunity of using the laser device Nd:YAG for welding the parts with small dimensions and width, as we have explained with the examples presented above. The way the ray is sending forth allows a good control of energy in the working area, especially for thermal influences around the welding point and minim deformation for the welding materials.

The main advantages of laser using in the manufacturing technologies are:

- the possibility of manufacturing any steel or dielectric material, without taking into account its hardness, but we have to pay attention to its absorption power of radiations;

- the shortening of manufacturing time because of instantaneous way of process task;

- from the kind of the contact point of view, we may say it is not any deformation of the part, because of contactless characteristics;

- we may assess the manufacturing of parts with very small dimensions or with complex shapes;

- the process could be automatized entirely and could be done by applying the numerical control;

- we may place very accurately the part in front of laser ray with precise focal, so the accuracy is the highest one.

\section{References}

1. D. Besnea, O. Dontu, M. Avram, A. Spanu, C. Rizescu, T. Pascu, The $7^{\text {th }}$ International Conference on Advanced Concepts in Mechanical Engineering, ACME, Iasi, Romania (2016)

2. O. Dontu, J.L. Ocana Moreno, R. Ciobanu, M. Branzei, D. Besnea, , J. of Optoelectronics and Adv. Mat., 7, nr. 9-10 (2015)

3. R. Ciobanu, Gh.I. Gheorghe, O. Dontu, D. Besnea, D. Cioboata, The Romanian Review Precision Mechanics, Optics\&Mechatronics, 48 (2015)

4. R. Ciobanu, O. Dontu, D. Besnea, A. Spanu, I. Avarvarei, AMM 811 (2015) 
5. D. Besnea, O. Dontu, Gh.I. Gheorghe, R. Ciobanu, A. Cuta, Laser microwelding of mechatronics components, Romanian Review Precision Mechanics, Optics\&Mechatronics, 46 (2014)

6. R. Ciobanu, O. Dontu, D. Besnea, V. Constantin, D. Cioboata, , $5^{\text {th }}$ Internat. Conf. on Materials Science and Technologies, 15-17 Octombrie, Bucharest, Romania (2014)

7. ISO 2919 Surse inchise de radiatii nucleare

8. ISO 9978/1992 Radioprotectie

9. ROFIN - Laser micro welding SW 6002

10. Microscope electronic Inspect S, FEI, Netherlands- Technical book

11. Hardness tester SHIMADZU HMV - 2TE, Japan - Technical book 